\title{
Incidence and Prognosis of Atrial Fibrillation in Patients With Sepsis
}

\author{
Gretchen L. Wells ${ }^{\mathrm{a}, \mathrm{c}}$, Peter E. Morris ${ }^{\mathrm{b}}$
}

\begin{abstract}
Background: Although the mortality rate among patients with sepsis is declining, the incidence of both sepsis and sepsis-related deaths is increasing, likely due to its presence in a growing elderly population. As atrial fibrillation is more common in the elderly, we hypothesize that its presence will be associated with greater mortality among patients with sepsis.
\end{abstract}

Methods: The Medical Intensive Care Unit (MICU) database of a large tertiary care medical center was queried for sepsis-related codes and atrial fibrillation.

Results: Atrial fibrillation was associated with older age and a higher mortality in this series of patients with sepsis.

Conclusions: Whether atrial fibrillation is a marker of disease severity or contributes to mortality is uncertain. Further studies are necessary to determine optimal management.

Keywords: Atrial fibrillation; Sepsis; Mortality; Elderly; Arrhythmia

Manuscript accepted for publication October 14, 2011

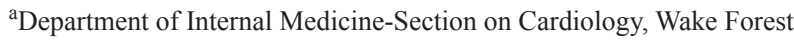
School of Medicine, Medical Center Boulevard, Winston-Salem, NC, USA

${ }^{b}$ Department of Internal Medicine-Section on Pulmonary/Critical Care, Wake Forest School of Medicine, Medical Center Boulevard, Winston-Salem, NC, USA

${ }^{c}$ Corresponding Author: Gretchen L. Wells, Cardiology Section Wake Forest University School of Medicine, Medical Center Boulevard Winston-Salem, NC 27157-1045, USA.

Email: gwells@wakehealth.edu

doi:10.4021/cr108w

\section{Introduction}

An emerging challenge in the management of the ICU patient with sepsis is atrial fibrillation. While the current mortality rate among patients with sepsis is declining [1], likely due to improvements in the management of the critically-ill patient including early goal-directed therapy [2], the incidence of sepsis and the number of sepsis-related deaths are increasing, due largely to a growing elderly population [3]. As atrial fibrillation is most common in older patients, we performed a retrospective review over a one-year period of ICU patients hospitalized with sepsis, and we found that atrial fibrillation was not only common, but it was associated with increased mortality.

\section{Materials and Methods}

From January 1, 2008 to December 31, 2008, 1466 patients were admitted to the Medical Intensive Care Unit (MICU) at Wake Forest University Baptist Medical Center, an 885bed university hospital. All patients admitted to the MICU were queried for sepsis-associated ICD-9 codes (785.52 and 995.92). Patients with a recent myocardial injury during the hospitalization or a malignancy identified by ICD-9 codes were excluded.

\section{Results}

Four hundred sixty-five of these patients were identified with either severe sepsis or septic shock [4]. Of these 465 patients (203 women and 262 men) with a sepsis-associated ICD-9 code, 132 (54 women and 78 men) developed atrial fibrillation identified by telemetry and confirmed by a faculty cardiologist interpretation of an ECG.

The mean age in the ICU population during this period was $63 \pm 17$ years, and the mean age in the sepsis population was $62 \pm 16$ years. However, in the patients with both sepsis and atrial fibrillation, the mean age was $72 \pm 13$ years.

Of the patients with sepsis who developed atrial fibrilla- 


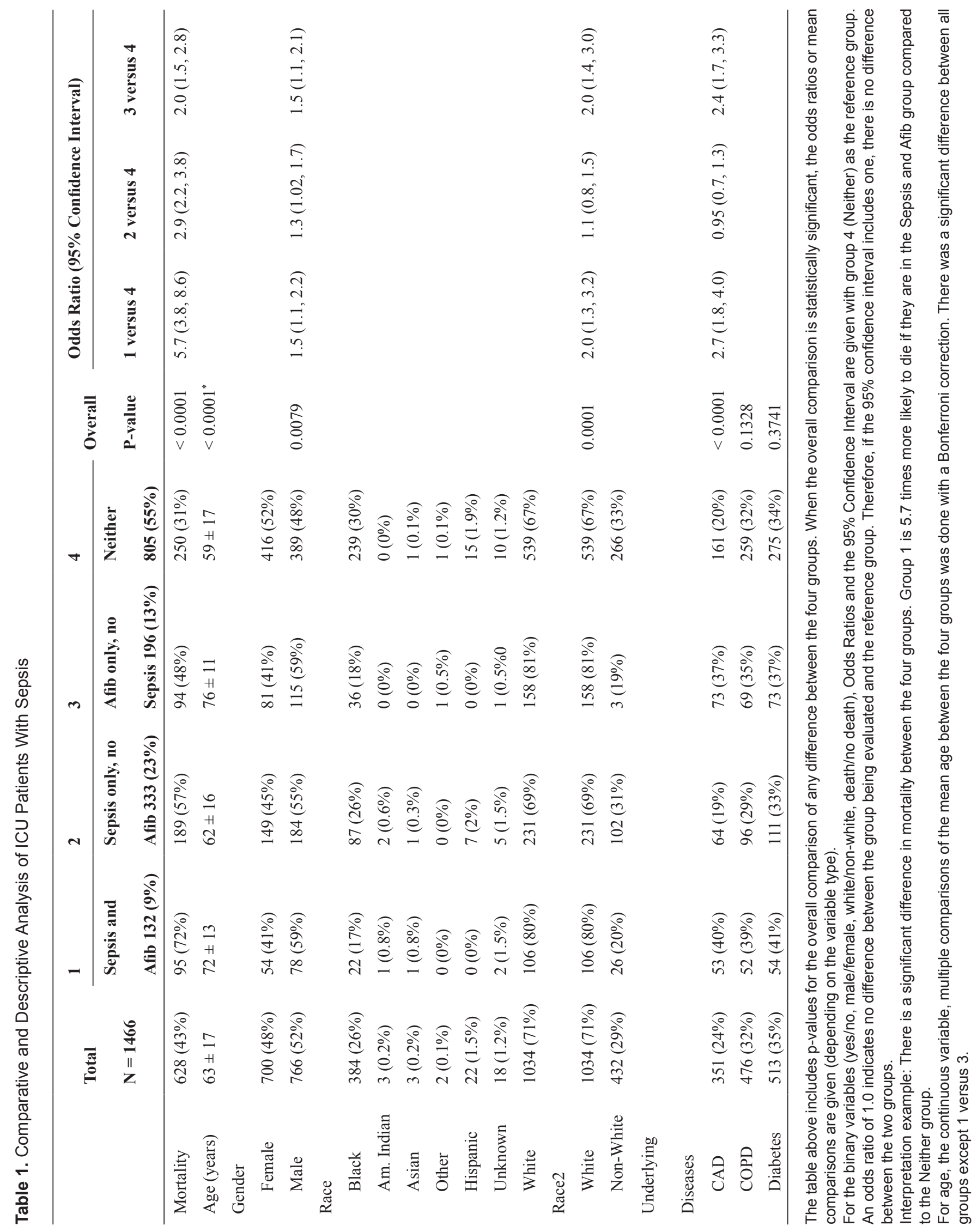




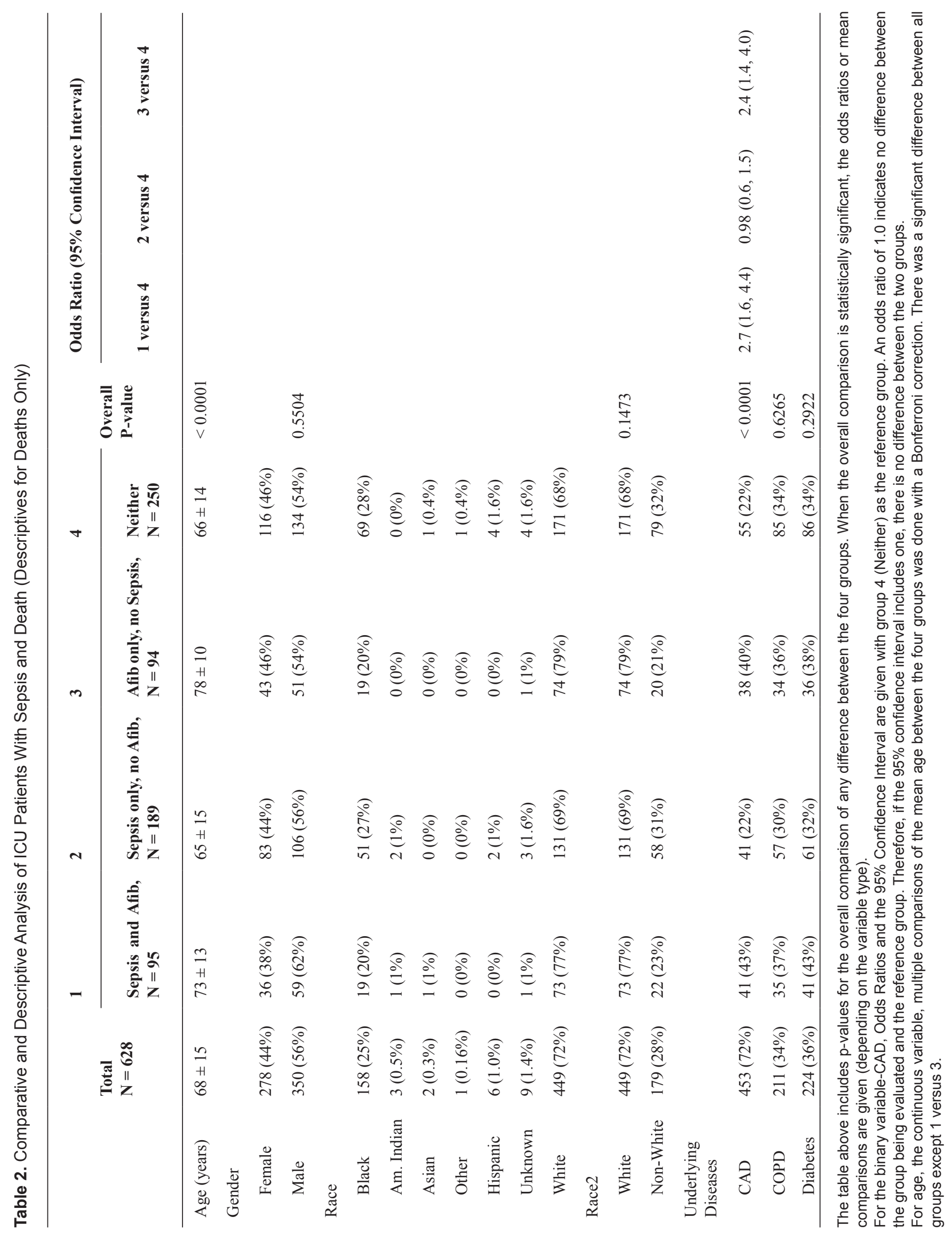


tion, there was a much higher percentage of coronary artery disease, chronic obstructive pulmonary disease and diabetes mellitus (40\%, 39\% and 41\%, respectively) compared with those patients with sepsis who did not develop atrial fibrillation $(19 \%, 29 \%$ and 33\%, respectively). However, it appears that these were also risk factors for the development of atrial fibrillation in the general MICU population (i.e. those without sepsis) as well. (Table 1)

Atrial fibrillation was strongly associated with in-hospital mortality in the MICU patient $(\mathrm{P}<0.001)$. Of the patients without sepsis who developed atrial fibrillation, 94 of these 196 individuals died (48\%). Even more striking is the mortality in the group with sepsis who developed atrial fibrillation where 95 of 132 (72\%) patients died. (Table 2)

\section{Discussion}

Critically-ill patients frequently develop cardiac arrhythmias (up to $90 \%$ in primary cardiovascular patients); however, these groups often include those patients post major surgery, multiple trauma, those with severe underlying lung disease, malignancies, renal failure, and neurologic diseases as well as sepsis [5, 6]. Only one report described 25 of 81 patients admitted with sepsis (31\%) developing paroxysmal atrial fibrillation [7]. This finding is similar to that of ours in which 132 out of 333 patients with sepsis (40\%) developed atrial fibrillation.

Cardiac involvement occurs in septic patients, even without septic shock. The ejection fraction (fraction of enddiastolic volume ejected with each beat) is often reduced, likely through several mechanisms including inflammatory mediators [8]. It is plausible that the cardiac involvement would include the development of atrial fibrillation. However, one study did not link inflammation (identified by Creactive protein levels) with the development of post-operative atrial fibrillation [9].

Early goal-directed therapy of sepsis was designed to optimize cardiac preload, afterload, and contractility and was associated with a significant mortality benefit. However, large-volume infusion results in less of an increase in left ventricular stroke work index in patients with sepsis and septic shock as compared to other critically-ill control subjects [10]. Whether large volume infusion reduces or increases atrial arrhythmias is unknown.

The prevalence of atrial fibrillation is estimated to be 0.4 to $1 \%$ of the general population, increasing with age to $>8 \%$ in those over 80 years of age. It is complicated by an increased risk of stroke, heart failure and mortality. Anticoagulation, rate control and rhythm control strategies are treatment options; however, large studies have not demonstrated that rhythm control is superior to rate control in certain populations [11]. Some studies have focused on the prevention of atrial fibrillation, e.g., amiodarone, angioten- sin-converting enzyme inhibitors and 3-hydroxy-3-methylglutaryl coenzyme A reductase inhibitors (statins) with limited success [12]. Finally, catheter ablation for paroxysmal atrial fibrillation has emerged as an effective treatment in selected patients [13].

Guidelines and strategies for the acute and chronic management of atrial fibrillation are available for many populations [14, 15]. However, after an exhaustive review of the literature, Kanji et al. could not recommend a treatment strategy for atrial fibrillation in the noncardiac, critically-ill adult patient due to a lack of clinical trials) [16]. Management decisions are even more complicated among typical ICU patients who are elderly, have multiple comorbidities, and have been excluded from clinical trials of atrial fibrillation [17].

Our series, as well as others, demonstrate that atrial fibrillation frequently complicates the course of sepsis and results in increased mortality [5, 7, 18-20], although one series reported no impact on the risk of in-hospital mortality [6]. Whether this arrhythmia is a marker of critical illness or the cause of death is uncertain. Further studies are warranted to determine the optimal management of atrial fibrillation in this older, high-risk, critically-ill population.

\section{Acknowledgements}

The authors would like to acknowledge and thank Leah Passmore Griffin, M.S., Biostatistician in the Division of Public Health Sciences-Department of Biostatistical Sciences at Wake Forest School of Medicine, for statistical analysis of the data. Drs. Gretchen L. Wells and Peter E. Morris are employed by Wake Forest Health Sciences.

\section{References}

1. Martin GS, Mannino DM, Eaton S, Moss M. The epidemiology of sepsis in the United States from 1979 through 2000. N Engl J Med. 2003;348(16):1546-1554.

2. Rivers E, Nguyen B, Havstad S, Ressler J, Muzzin A, Knoblich B, Peterson E, et al. Early goal-directed therapy in the treatment of severe sepsis and septic shock. N Engl J Med. 2001;345(19):1368-1377.

3. Angus DC, Linde-Zwirble WT, Lidicker J, Clermont G, Carcillo J, Pinsky MR. Epidemiology of severe sepsis in the United States: analysis of incidence, outcome, and associated costs of care. Crit Care Med. 2001;29(7):13031310.

4. Bone RC, Balk RA, Cerra FB, Dellinger RP, Fein AM, Knaus WA, Schein RM, et al. Definitions for sepsis and organ failure and guidelines for the use of innovative therapies in sepsis. The ACCP/SCCM Consensus Conference Committee. American College of Chest Physicians/Society of Critical Care Medicine. Chest. 
1992;101(6):1644-1655.

5. Artucio H, Pereira M. Cardiac arrhythmias in critically ill patients: epidemiologic study. Crit Care Med. 1990;18(12):1383-1388.

6. Annane D, Sebille V, Duboc D, Le Heuzey JY, Sadoul $\mathrm{N}$, Bouvier E, Bellissant E. Incidence and prognosis of sustained arrhythmias in critically ill patients. Am J Respir Crit Care Med. 2008;178(1):20-25.

7. Salman S, Bajwa A, Gajic O, Afessa B. Paroxysmal atrial fibrillation in critically ill patients with sepsis. $\mathrm{J}$ Intensive Care Med. 2008;23(3):178-183.

8. Parrillo JE. Pathogenetic mechanisms of septic shock. N Engl J Med. 1993;328(20):1471-1477.

9. Ahlsson AJ, Bodin L, Lundblad OH, Englund AG. Postoperative atrial fibrillation is not correlated to C-reactive protein. Ann Thorac Surg. 2007;83(4):1332-1337.

10. Ognibene FP, Parker MM, Natanson C, Shelhamer JH, Parrillo JE. Depressed left ventricular performance. Response to volume infusion in patients with sepsis and septic shock. Chest. 1988;93(5):903-910.

11. Wyse DG, Waldo AL, DiMarco JP, Domanski MJ, Rosenberg Y, Schron EB, Kellen JC, et al. A comparison of rate control and rhythm control in patients with atrial fibrillation. N Engl J Med. 2002;347(23):1825-1833.

12. Adam O, Neuberger HR, Bohm M, Laufs U. Prevention of atrial fibrillation with 3-hydroxy-3-methylglutaryl coenzyme A reductase inhibitors. Circulation. 2008;118(12):1285-1293.

13. Oral H, Scharf C, Chugh A, Hall B, Cheung P, Good E, Veerareddy $\mathrm{S}$, et al. Catheter ablation for paroxysmal atrial fibrillation: segmental pulmonary vein ostial ablation versus left atrial ablation. Circulation.
2003;108(19):2355-2360.

14. Wann LS, Curtis AB, January CT, Ellenbogen KA, Lowe JE, Estes NA, 3rd, Page RL, et al. 2011 ACCF/ AHA/HRS focused update on the management of patients with atrial fibrillation (updating the 2006 guideline): a report of the American College of Cardiology Foundation/American Heart Association Task Force on Practice Guidelines. Circulation. 2011;123(1):104-123.

15. Camm AJ, Kirchhof P, Lip GY, Schotten U, Savelieva I, Ernst S, Van Gelder IC, et al. Guidelines for the management of atrial fibrillation: the Task Force for the Management of Atrial Fibrillation of the European Society of Cardiology (ESC). Eur Heart J. 2010;31(19):2369-2429.

16. Kanji S, Stewart R, Fergusson DA, McIntyre L, Turgeon AF, Hebert PC. Treatment of new-onset atrial fibrillation in noncardiac intensive care unit patients: a systematic review of randomized controlled trials. Crit Care Med. 2008;36(5):1620-1624.

17. Kitzman DW, Rich MW. Age disparities in heart failure research. JAMA. 2010;304(17):1950-1951.

18. Goodman S, Weiss Y, Weissman C. Update on cardiac arrhythmias in the ICU. Curr Opin Crit Care. 2008;14(5):549-554.

19. Sleeswijk ME, Van Noord T, Tulleken JE, Ligtenberg JJ, Girbes AR, Zijlstra JG. Clinical review: treatment of new-onset atrial fibrillation in medical intensive care patients--a clinical framework. Crit Care. 2007;11(6):233.

20. Meierhenrich R, Steinhilber E, Eggermann C, Weiss $\mathrm{M}$, Voglic S, Bogelein D, Gauss A, et al. Incidence and prognostic impact of new-onset atrial fibrillation in patients with septic shock: a prospective observational study. Crit Care. 2010;14(3):R108. 